\title{
O Ensino Médio noturno e o mundo do trabalho: rasura e permanência (1971-1996)
}

\author{
Deane Monteiro Vieira Costa* \\ Larissa Zanin** \\ Maria Amélia Dalvi***
}

\section{Resumo}

Este artigo problematiza a aparentemente necessária relação entre escolarização e trabalho na legislação brasileira referente ao Ensino Médio (em especial, considera as leis 5.692/71, 7.044/82 e 9.394/96) e defende uma visão menos estereotipada do jovem e do adulto estudante e das razóes que os levam a buscar a escola e a formação no turno noturno. Essa tentativa de fazer uma nova leitura do(a) aluno(a) da escola noturna atesta que um modelo próprio para os cursos noturnos, em que o trabalho seja o principal - e muitas vezes o único - eixo norteador, é inviável e, mais do que isso, indesejável. Mostra que os significados compartilhados e os símbolos específicos que sinalizam o pertencimento a um determinado grupo, para o aluno do noturno, não são (apenas ou principalmente) os relacionados ao mundo do trabalho. Pelo contrário, na maioria dos casos, o estudante trabalhador tem frequentemente dificuldades em se inserir socialmente no(s) grupo(s) que se forma $(\mathrm{m})$ no turno noturno, nas escolas. Precisamos nos atentar para o fato de que estudantes do noturno não são necessariamente trabalhadores - e mais: preocupam-se com o estereótipo de que o ensino a eles facultado é "mais fraco" em relação àquele facultado aos estudantes dos turnos matutino ou vespertino, em razão de, supostamente, terem menos tempo disponível para a escola.

Palavras-chave: Ensino Médio, legislação, políticas públicas, trabalho, turno noturno.

* Licenciada em História, mestre em Educação e doutoranda pelo Programa de Pós-Graduaçâo em Educação da Universidade Federal do Espírito Santo (Ufes) e professora do Centro Universitário Vila Velha (UVV). E-mail: deane_vieira@ig.com.br.

** Licenciada em Artes, mestre em História e doutoranda pelo Programa de Pós-Graduação em Educação da Ufes e servidora do Instituto Federal do Espírito Santo (Ifes). E-mail: larissa_zanin@hotmail.com.

*** Licenciada e mestre em Letras e doutoranda pelo Programa de Pós-Graduação em Educação da Ufes e servidora da mesma instituiçấo. E-mail: mariaameliadalvi@gmail.com. 
Attending Secondary School at night and work environment: problems and permanence (1971-1996)

\begin{abstract}
This article focuses on the apparently obligatory relationship between schooling and work in Brazilian law (in particular laws 5.692/71, 7.044/82 and 9.394/96). It defends a less stereotyped view of both young and adult students and the reasons why they choose to study at night. This attempt at presenting a new image of the night school student defends the argument that a specific model for night courses in which work is the main - and frequently the only - guideline is unfeasible and, furthermore, undesirable. It shows that the shared meanings and the specific symbols that signal a student's belonging to a given group are not, solely or principally, those signs related to the labor environment. On the contrary, in most cases, it is frequently difficult in social terms for the working student to become part of pre-existing night school groups. One must consider the fact that night school students are not necessarily workers - and furthermore, that they are concerned about the stigma that the education they receive is of a lower quality than that of their morning or afternoon colleagues, because supposedly they have less time available for school.
\end{abstract}

Keywords: secondary school, Brazilian educational law, public policies, work, night school.

Para melhor compreender o Ensino Médio brasileiro, em especial nas três últimas décadas do século XX e nos primeiros anos do século XXI, é imprescindível analisar o contexto sócio-histórico e o ambiente político e pedagógico em que se deu a elaboraçáo e a implantação das propostas educacionais indicadas pelas leis 5.692/71, 7.044/82 e 9.394/96, visando o entendimento da educação como uma política pública (Azevedo, 1997) e, no caso específico do Ensino Médio noturno, como uma política pública voltada à juventude trabalhadora (Abad, 2003). Embora a lei 5.692/71 não deva ser pensada sem se levar em consideraçáo a 4.024/61, que a antecede, advertimos, de início, que, dados os limites diminutos deste artigo, sua incorporação às análises será efetivada em outro espaço.

A educação voltada para o trabalho, a partir da lei 5.692/71, passa a fazer parte do currículo dos ensinos de primeiro e segundo graus (hoje, Ensinos Fundamental e Médio). O ensino de primeiro grau deveria ocupar-se precipuamente da educação geral (entendida como saberes elementares, relativos à formação e à inserção social etc.), fornecendo uma base comum de conhecimentos a todos em processo de escolarização. Mas, ainda nesse nível, também seria necessária uma iniciação às aptidóes exigidas pelo mundo do trabalho, sendo incluída nas séries finais do ensino de primeiro grau, em caráter não dominante, uma formação profissional 
elementar. A habilitação profissional propriamente dita seria dominante no segundo grau (Romanelli, 2000). A lei em questão prevê textualmente que esse nível de ensino esteja em sintonia com o "mercado de trabalho local ou regional, à vista de levantamentos periodicamente renovados [...], em consonância com as necessidades desenvolvimentistas" (Brasil, 1971, lei 5.692 , art. $\left.5^{\circ}\right)$.

Como se deduz, o governo militar então vigente tentou vincular o sistema educacional aos interesses econômico-mercadológicos, políticos e ideológicos aos quais se submetia. Seu objetivo, ao promover o chamado "milagre brasileiro" - "milagre" irrealizável sem a formação programática de mão de obra que, ao menos em tese, atendesse às demandas do mercado -, era escamotear as arbitrariedades de um regime ditatorial, angariando, contudo, tanto quanto possível, aprovação popular, mediante a instrumentalização de um discurso que esteve a serviço das classes detentoras dos meios de produção: o do progresso, o da modernização (Kuenzer, 2000).

Todavia, ao substituir a equivalência entre os ramos secundário e propedêutico pela habilitação profissional compulsória, no segundo grau, a educação brasileira teve como efeitos "não produzir nem a profissionalização nem o ensino propedêutico” (Santos, 2007, p. 219). Isso porque contribuíram para o fracasso do ensino de segundo grau profissionalizante "a falta de recursos materiais e humanos para a manutenção, por parte do poder público, de uma extensa rede de escolas" e a "resistência dos empresários em admitir nos quadros de suas empresas os profissionais oriundos dos cursos de segundo grau" como mão de obra efetivamente habilitada às funçóes para as quais estava diplomada (Santos, 2007, p. 219). A exceção, nesse aspecto, deve ser feita àqueles profissionais formados pelas Escolas Técnicas Federais ou Centros Federais de Educação Tecnológica, que nos anos 1960 e 1970 "eram recrutados, quase sem restriçóes, pelas grandes empresas privadas ou estatais" (Santos, 2007, p. 220).

Outro fator a ser considerado quanto à profissionalização compulsória propugnada pela lei 5.692/71 é que o trabalhador instrumental, na maioria dos casos, ficava retido pelos altos índices de evasão e repetência, sem concluir formalmente sua habilitação profissional. Esse fato, de saída, dá mostras de que se, aparentemente, a profissionalização deveria abranger a todos, no entanto, só atingia, em geral, os mais ou menos remediados, ou a classe média baixa, e não os realmente pobres, pois os determinantes desta 
realidade "estavam fora da escola, ou seja, eles estavam presentes na estrutura de classes" (Santos, 2007, p. 220).

Para entender a lógica que organiza essa opção do governo militar, é preciso perceber que,

a Universidade continuava a ser fator de mobilidade social, como o era antes; o crescente aumento da demanda social de estudos superiores como decorrentes desse processo, por sua vez, decorre da impossibilidade de a massa de estudantes profissionalizar-se mais cedo. A profissionalizaçáo do nível médio, portanto, era vista como uma exigência que teria como resultado selecionar apenas os mais capazes para a Universidade, dar ocupação aos menos capazes e, ao mesmo tempo, conter a demanda de educação superior em limites mais estreitos. (Romanelli, 2000, p. 235)

Preparar alguns alunos para o Ensino Superior e outros para o mundo do trabalho, alijando-os da possibilidade de escolher seguir ou não para a universidade, sempre foi uma questão controversa, a despeito dos argumentos utilizados para sua justificação. Numa análise rápida, o primeiro dado a ser apontado é que essa diferenciação entre formação para o Ensino Superior e formação para a inserção imediata no mercado de trabalho dá-se a ver como expressão evidente da tendência à perpetuação do saber - e do poder - nas mãos de poucos privilegiados.

Ao longo da história da nossa educação, a diferenciação que estamos apontando manifestou-se tanto nas propostas legais quanto na efetivação dos currículos escolares formais. Uma evidência disso, que permanece ainda hoje, é dada pela comparação entre o currículo proposto (na atualidade, a partir de uma flexibilização não de todo esclarecida) para o Ensino Médio diurno e aquele proposto para o noturno. A dualidade acentuada pela política educacional moldada nos gabinetes militares persiste: o Ensino Médio deve ser "propedêutico", abordando tão somente conteúdos básicos das áreas de humanidades, exatas e biológicas, preparando o estudante para ingressar na universidade, ou deve ser profissionalizante, preparando o aprendiz para o mundo do trabalho ao mesmo tempo em que o familiariza a disciplinas gerais? O nó górdio é que, se, por um lado, a profissionalização a que poderíamos chamar "precoce" pode contribuir para a permanência do jovem na escola, subsidiando, inclusive, seus estudos em nível superior, por outro, esta opção, como vimos, pode revelar-se perniciosa. 
Articulando a diferenciação entre o Ensino Médio diurno e o noturno à opção por uma formação propedêutica ou profissional, Lins (2007, p. 58) afirma que,

hoje é possível verificar que ainda há uma dicotomia mais acentuada e que, de certa forma, continua cristalizando uma perene dualidade, nesse caso, mais especificamente entre o ensino médio diurno e o noturno. $\mathrm{O}$ primeiro atenderia ao público pertencente a segmentos de classe média, cujas famílias têm alguma condiçấo de manter filhos sem que esses precisem exercer trabalho assalariado, direcionando-os para de alguma forma cursar o ensino superior. O outro modelo atenderia aos mais desprovidos de condiçóes financeiras, que trabalham durante o dia.

Fracassada, no regime militar, a política de profissionalização universal e compulsória no ensino de $2^{\circ}$ grau, pelos motivos expostos e, ainda, pela produção e divulgação de um pensamento crítico-reflexivo (quer por parte dos estudiosos de nossa educação, quer por parte dos homens comuns a ela submetidos), surgiu a lei 7.044/82, que alterou a determinação de "qualificação para o trabalho" para "preparação para o trabalho". A profissionalização passa, assim, a ser um indicativo e não uma obrigatoriedade (Lins, 2007).

O novo contexto propiciado pela abertura política permitiu que o projeto de lei do senador Darcy Ribeiro fosse levado a cabo, dando-se, então, a promulgação da lei 9.394/96, nossa atual LDB. Esta incorpora o Ensino Médio à "educação básica"; transforma a "formação ética", a "autonomia intelectual" e o "pensamento crítico" em finalidades dessa modalidade de ensino; e determina que à escola caiba não só a reprodução de uma cultura e de uma sociedade, mas a produção de indivíduos críticos e autônomos.

De acordo com Perry Anderson (1995), o neoliberalismo propôs, como solução à crise do modelo econômico característico do pós-guerra, um Estado forte, para enfraquecer o poder dos sindicados e instituir uma disciplina orçamentária, mas parco - e poderíamos dizer omisso - em gastos sociais e intervençóes econômicas. No Brasil, a partir da década de 1990, as políticas neoliberais desencadearam, programaticamente, o aumento das desigualdades sociais - com o consequente estabelecimento de uma massa de desempregados, vistos como reserva de mercado -, o enfraquecimento das forças sindicais e dos movimentos populares e a restrição a políticas sociais relativas a emprego, saúde, educação, moradia etc. 
No caso específico da educação, o Estado neoliberal projetou-se na consolidação da chamada nova LDB, ou lei 9.394/96, que teve como objetivo adaptar os sistemas de ensino às exigências da economia globalizada, por meio de um discurso centrado na ideia de competências e, ainda, por meio do estabelecimento de um currículo mínimo nacional. Outro traço neoliberal identificável na nova LDB é a proposta de descentralização do setor educacional, mediante a transferência da responsabilidade, da gestão e da execução dos serviços educacionais para estados e municípios; e, ainda, mediante parcerias firmadas entre os setores público e privado. Contudo, se, por um lado, observamos a descentralização estatal da responsabilidade, da gestão e da execução, por outro, observamos a centralização estatal no controle sobre a qualidade - bem entendida como atendimento às exigências da economia globalizada para a formação programática de mão de obra - dos serviços educacionais. Dentre os mecanismos instituídos, podemos destacar o Enem, o Enade, a Prova Brasil, a Provinha Brasil e o Saeb, bem como a participação voluntária em programas como o Pisa.

As modificaçóes previstas pela nova LDB dizem respeito, também, no recorte que mais de perto nos interessa, à preparação para o exercício de profissóes técnicas no Ensino Médio, facultando-a, desde que seja "atendida a formação geral" do educando. Souza (2003, p. 32) critica esse aspecto da legislação por não corresponder à prática real, uma vez que,

no interior das nossas escolas, a educação de nível médio tem se reduzido ao desenvolvimento de habilidades e competências, em detrimento daquilo que deveria ser sua essência: a formaçáo. Essa carência de conteúdo curricular em favor das habilidades é enfatizada pela [...] capacidade de "aprender a aprender" que possibilita uma "adaptação flexível" às condições mutáveis do mercado, não almejando a possibilidade crítica e de mudança social, mas a adaptação à realidade que se fizer presente. A legislação confere à educação de nível médio um caráter de ensino de técnicas e estratégias de inserção social, o que pressupóe não a crítica, mas a aceitação da realidade.

Pelos motivos expostos, conclui-se que, a despeito da aparente evolução da legislação educacional brasileira, especificamente no que concerne à formação do jovem no antigo segundo grau - hoje, Ensino Médio -, a realidade dista daquilo que poderia ser considerado ideal. E o caso é mais grave quando considerada a discriminação de que o ensino noturno frequentemente é 
vítima: deve ser menos "puxado", mais voltado para o mundo "prático", deve levar em conta a "natural" dificuldade do aluno trabalhador, etc. O que está em jogo, nesta situação, é a já datada controvérsia entre quantidade-qualidade (Santos Filho; Gamboa, 2000): oferecer ensino amplo e irrestrito - "inclusive" àqueles que não têm condições de permanecer na escola sem trabalhar e, portanto, precisam estudar à noite, com carga horária reduzida, etc. - ou ensino de qualidade? A perversidade disto é que se estabelece uma falsa dicotomia: articula-se maniqueisticamente qualidade e quantidade a questóes de classe: os remediados ou privilegiados, aqueles que, com um pouco de "esforço pessoal", podem alcançar um "bom" curso técnico ou mesmo o Ensino Superior versus os pobres, os trabalhadores, os menos capazes, aqueles que não vão nem sequer "passar na porta" da universidade, perpetuando uma concepção de política pública para a juventude formulada no contexto de um Estado autoritário e neoliberal (Przeworski, 1989). O ensino noturno tende, assim, a ser visto como a última e única opção para os jovens pobres: a ampliação do acesso, nessa perspectiva, seria fruto da "distribuição" de "inclusão social" por parte do Estado (Freitas; Bicas, 2009, p. 22).

Em História social da educação no Brasil (1926-1996), Marcos Cezar de Freitas e Maurilane de Souza Bicas (2009, p. 18-20) sinalizam que,

a construção e o acesso a esse "bem público" primordial que é a educação escolar se deu no bojo da consolidação de uma sociedade reconhecidamente concentradora de riqueza, benefícios e poder decisório. [...] Esse "lugar" da escola também diz respeito às demarcaçôes quotidianas do "lugar de cada um”. [...] Se instalou, por obra da cristalização dos mais variados repertórios de opiniáo e de preconceitos sociais, o diagnóstico simplista de que a escola pública poderia ser "competente", mas "piorou" quando (e porque) o povo teve acesso aos seus domínios. (grifo nosso)

Frigotto (1998) vem dialogando com os desafios teórico-metodológicos da relação trabalho-educação no contexto da crise dos paradigmas das ciências sociais. Assim, após reconstituir a lógica interna e a gênese histórica da teoria do capital humano (Schultz, 1973), mostra que a escola náo é produtiva a serviço dos indivíduos indistintamente, no seio de uma sociedade sem antagonismos, como supunham os adeptos da teoria do capital humano. Também não é ela produtiva a serviço exclusivo do capital, como pretendiam os críticos (reprodutivistas) da referida teoria. E nem mesmo é ela 
simplesmente improdutiva, como pretendeu a crítica da crítica à teoria do capital. De acordo com Saviani (2006), o que Frigotto procura fazer é captar a existência do vínculo entre escola e trabalho, mas percebendo, ao mesmo tempo, que não se trata de um vínculo direto e imediato, mas indireto e mediato. Ainda de acordo com Saviani (2006), se, para a teoria do capital humano, bem como para seus críticos, a escola é simplesmente produtiva, a escola (imediatamente) improdutiva é (mediatamente) produtiva.

Questionamo-nos, assim, tendo como ponto de partida as reflexóes de Frigotto e de Saviani, acerca da preocupação com a relação entre educaçáo e trabalho, especialmente quando se trata do Ensino Médio, de que a legislação educacional dá mostras, desde os anos 1970 à atualidade, tendo em vista a passagem dos ideais socialistas aos neoliberais, tal como expóem Adam Przeworski (1989) e, principalmente, Perry Anderson (1995). E formulamos a seguinte questão: Políticas públicas formuladas no âmbito da educação brasileira, mais especificamente para o Ensino Médio noturno, têm que, necessariamente, investir-se da possibilidade de profissionalização e de adequação (como eufemismo recorrente de "redução" ou "enxugamento") curricular, em detrimento de "formação ética", "autonomia intelectual" e "pensamento crítico" (considerando-se que, como vimos, a preparação para o exercício de profissóes técnicas no Ensino Médio em consonância à "formação geral" não corresponde à realidade)?

Em busca da resposta, somos obrigados a considerar o que Marques (1997) nos lembra: ver no aluno da escola noturna somente o jovem que trabalha inviabiliza qualquer projeto pedagógico que procure responder às suas necessidades - inclusive porque muitos dos jovens que estudam à noite nem sequer estáo inseridos no mundo do trabalho; e, entre aqueles que estão inseridos, o índice de desemprego é altíssimo. Assim, parece-nos que o(a) jovem aluno(a) da escola noturna apresenta particularidades que vão além das de um jovem trabalhador. Muitas vezes procuram na escola não só a qualificação ou aprimoramento para o trabalho, mas também (e às vezes apenas) um espaço de sociabilidade e de troca de experiências que ultrapassam as exigências institucionais.

Essa tentativa de fazer uma nova leitura do(a) jovem aluno(a) da escola noturna defende que um modelo próprio para os cursos noturnos - que torne seus sujeitos estereotipados: por exemplo, são necessariamente trabalhadores e é nisto que a escola deve basear-se para organizar seu currículo formal e seu cotidiano - é inviável e, mais do que isso, indesejável. Enten- 
demos, como Dayrell, que as culturas juvenis "representam modos de vida específicos e práticas cotidianas que expressam um conjunto de significados compartilhados, um conjunto de símbolos específicos que sinalizam o pertencimento a um determinado grupo. [...] Essa diversidade também é dada pelo contexto de origem social e pelas condiçóes concretas de vida nas quais os jovens são socializados" (Dayrell, 2003, p. 187-188). Parece-nos, como professoras com histórico de atuação no turno noturno, que os significados compartilhados e os símbolos específicos que sinalizam o pertencimento a um determinado grupo, para o aluno do noturno, não são os relacionados ao mundo do trabalho; pelo contrário: na maioria dos casos, o estudante trabalhador tem frequentemente dificuldades em inserir-se socialmente no(s) grupo(s) que se formam no turno noturno, nas escolas. Estudantes do turno noturno não são necessariamente trabalhadores - e mais: preocupam-se com o estereótipo de que o ensino a eles facultado é "mais fraco" em relação àquele facultado aos estudantes do turno matutino ou vespertino, em razão de, supostamente, terem menos tempo disponível para a escola.

Pôr todos os estudantes do turno noturno na condição de alunos trabalhadores é desconsiderar aquilo para o que Guillermina Tiramonti chama a atenção, em outro contexto:

La histórica desigualdad [...] genera formaciones culturales diversas que requieren a su vez propuestas diferenciadas. En un medio fragmentado, las propuestas que interpelan e incorporan positivamente a determinados sectores socio-culturales resultan expulsivas para otros o inadecuado para actualizar sus potencialidades cognitivas y formativas. (Tiramonti, 1997, s. p.)

Assim, embora não tenhamos respostas conclusivas acerca de como efetivar currículos e práticas no Ensino Médio noturno, considerando que, na atualidade, ele não diz respeito exclusivamente - e nem mesmo privilegiadamente - aos trabalhadores assalariados, entendemos que não se pode escamotear nossas incertezas com um pragmatismo reducionista. Ou seja, o aluno da escola pública noturna tem direito a uma educação formal em pé de igualdade com o aluno da escola matutina e/ou vespertina, sem a priorismos cujas únicas justificativas sejam a idealização do perfil do estudante e a preguiça em pensar que um novo Ensino Médio noturno (no qual ser trabalhador, dona de casa, mãe solteira, aluno "indisciplinado", pobre etc. não justifique a má qualidade e nem a irresponsabilidade dos profissionais e das instituiçóes) é possível. 


\section{Referências}

ABAD, M. Crítica política das políticas de juventude. In: FREITAS, M. V. de; PAPA, F. C. (Org.). Políticas públicas: juventude em pauta. São Paulo: Cortez: Ação Educativa Assessoria, Pesquisa e Informação: Fundação Friedrich Ebert, 2003. p. 13-32.

ANDERSON, P. Balanço do neoliberalismo. In: SADER, E. \& GENTILI, P. (Orgs.). Pós-neoliberalismo: as políticas sociais e o Estado democrático. Rio de Janeiro: Paz e Terra, 1995. p. 09-23.

AZEVEDO, J. M. L. de. A educação como política pública. Campinas, SP: Autores Associados, 1997.

BRASIL. Lei n. 4.024, de 20 de dezembro de 1961. Fixa as Diretrizes e Bases da Educação Nacional. Disponível em: <www.diariooficial.hpg.com.br/ fed_lei_4024_1961.htm>. Acesso em: 01 mar. 2009.

BRASIL. Lei n. 5.692, de 11 de agosto de 1971. Lei de Diretrizes e Bases da Educação Nacional. Disponível em: <www.planalto.gov.br/ccivil_03/Leis/ L5692.htm>. Acesso em: 01 mar. 2009.

BRASIL. Lei no 7.044, de 18 de outubro de 1982. Altera Dispositivos da Lei . 5.692, de 11 de agosto de 1971, referentes a profissionalização do ensino de 2. ${ }^{\circ}$ grau. Disponível em: <www.planalto.gov.br/ccivil_03/Leis/L7044. htm>. Acesso em: 01 mar. 2009.

BRASIL. Lei n. 9.394, de 20 de dezembro de 1996. Lei de Diretrizes e Bases da Educação Nacional. Disponível em: <www.portal.mec.gov.br/seesp/ arquivos/pdf/lei9394_ldbn1.pdf>. Acesso em: 01 mar. 2009.

DAYRELL, J. Escolas e culturas juvenis. In: FREITAS, M. V. de; PAPA, F. de C. (Org.). Políticas públicas: juventude em pauta. São Paulo: Cortez: Ação Educativa Assessoria, Pesquisa e Informação: Fundação Friedrich Ebert, 2003.

FREITAS, M. C. de; BICAS, M. de S. História social da educação no Brasil (1926-1996). São Paulo: Cortez, 2009.

FRIGOTTO, G. Educação e crise do trabalho: perspectivas de final de século. Petrópolis, RJ: Vozes, 1998. 
KUENZER, A. Ensino médio e profissional: as políticas do Estado neoliberal. 2. ed. São Paulo: Cortez, 2000.

LINS, E. C. Ensino médio no Brasil: aspectos históricos, legais e questôes do período noturno (1971-2006). Dissertação (Mestrado em Educação) Centro Universitário Salesiano de São Paulo, 2007.

MARQUES, M. O. da S. Escola noturna e jovens. Revista Brasileira de Educação. São Paulo, ANPED, n. 5/6, mai./jun./jul./ago./set./out./nov./dez. 1997.

PRZEWORSKI, A. Capitalismo e social-democracia. São Paulo: Companhia das Letras, 1989.

ROMANELLI, O. de O. História da Educação no Brasil. Rio de Janeiro: Vozes, 2000.

SANTOS, J. A. dos. A trajetória da educação profissional. In: LOPES, E. M. T. et al. (Orgs.). 500 anos de educação no Brasil. 3. ed. Belo Horizonte: Autêntica, 2007. p. 205-224.

SANTOS FILHO, J. C. dos; GAMBOA, S. S. (Org.). Pesquisa educacional: quantidade-qualidade. 3. ed. São Paulo: Cortez, 2000.

SAVIANI, D. O legado Educacional do Século XX. In: SAVIANI, D.; ALMEIDA, J. S. de; SOUZA, R. F. de; VALDEMARIN, V. T. O legado educacional do século XX no Brasil. São Paulo: Cortez, 2006.

SCHULTZ, T. W. O capital humano. Rio de Janeiro: Jorge Zahar, 1973.

SOUZA, R. M. de. Escola e juventude: o aprender a aprender. São Paulo: EDUC / Paulus, 2003.

TIRAMONTI, G. Los imperativos de las políticas educativas de los 90. Revista da Faculdade de Educação, v. 23. n.1-2. São Paulo, jan./dec. 1997. 